\title{
A narrative review of critical factors for better efficacy of CD19 chimeric antigen receptor $T$ cell therapy in the treatment of $B$ cell malignancies
}

\author{
Jia Liu ${ }^{1 \#}$, Luyao Wang ${ }^{1 \#}$, Hongbo Yang ${ }^{2}$, Meng Xing ${ }^{2}$, Shihai Liu ${ }^{3}$, Zhuang $\mathrm{Yu}^{2}$, Leina Ma ${ }^{2,4}$ \\ ${ }^{1}$ Department of Pharmacology, School of Pharmacy, Qingdao University, Qingdao, China; ${ }^{2}$ Department of Oncology, ${ }^{3}$ Department of Medical \\ Research Center, The Affiliated Hospital of Qingdao University, Qingdao University, Qingdao, China; ${ }^{4}$ Qingdao Cancer Institute, Qingdao \\ University, Qingdao, China \\ Contributions: (I) Conception and design: L Ma, Z Yu; (II) Administrative support: None; (III) Provision of study materials or patients: None; (IV) \\ Collection and assembly of data: None; (V) Data analysis and interpretation: None; (VI) Manuscript writing: All authors; (VII) Final approval of \\ manuscript: All authors. \\ \#These authors contributed equally to this work. \\ Correspondence to: Zhuang Yu, MD, PhD. Professor, Department of Oncology, The Affiliated Hospital of Qingdao University, Jiangsu Road, Qingdao \\ 266000, China. Email: yuzhuang2002@163.com; Leina Ma, MD, PhD. Associate Professor, Qingdao Cancer Institute, Qingdao University, Qingdao \\ 266000, China. Email: leinama@gmail.com.
}

\begin{abstract}
B cell malignancies are classified as different types such as B cell acute lymphoblastic leukemia (B-ALL), chronic lymphocytic leukemia (CLL) and B cell non-Hodgkin lymphoma (NHL) based on cell surface expression of various clusters of differentiation molecules. CD19 is a B cell lineage-specific antigen which is expressed on malignant B cells in patients with B-ALL, CLL and NHL. Adoptive transfer of T cells that are genetically modified to express a CD19-specific chimeric antigen receptor (CAR) represents a promising clinical strategy for patients with B cell malignancies. CD19-CAR T cell therapy has achieved high response rates and durable remissions on B cell malignancies. However, the efficacy of CAR-T therapy is still inefficient and the critical factors for better efficacy remain unclear. In this review, we summarized the critical factors for better efficacy of CD19 CAR-T cells in B-lineage malignancies including B-ALL, B-CLL and lymphoma. T cell persistence, lymphodepletion regimen, CD3/CD28 beads treatment and no IL-2 administration to $\mathrm{T}$ cells were positively associated with better responses. The method of enhancing the persistence of CAR-T cells need to be further optimized in order to improve the clinical efficacy in the treatment of B cell malignancies. In order to improve the therapeutic effect of CAR-T therapy, new therapeutic strategies should be developed to make factors which influence efficacy the more beneficial.
\end{abstract}

Keywords: CD19; CAR-T; cytokine release syndrome (CRS); B lineage malignancies

Submitted Feb 15, 2020. Accepted for publication Aug 10, 2020.

doi: $10.21037 /$ tcr-20-1044

View this article at: http://dx.doi.org/10.21037/tcr-20-1044

\section{Introduction}

B cell malignancies are classified as different types based on cell surface expression of various clusters of differentiation molecules. There are three main types of B-cell malignancies which are largely heterogeneous: B cell acute lymphoblastic leukemia (B-ALL), chronic lymphocytic leukemia (CLL) and B cell non-Hodgkin lymphoma
(NHL) $(1,2)$. Adoptive transfer of $\mathrm{T}$ cells engineered to express a chimeric antigen receptor (CAR) has emerged as an impactful targeted immunotherapy (Figure 1), showing prominent responses in refractory patients (3-5). In 2017, CAR-T therapy has achieved regulatory approval to conduct late phase clinical testing in the US (6). CARs comprise a tumor-targeting structure, which is often in the 

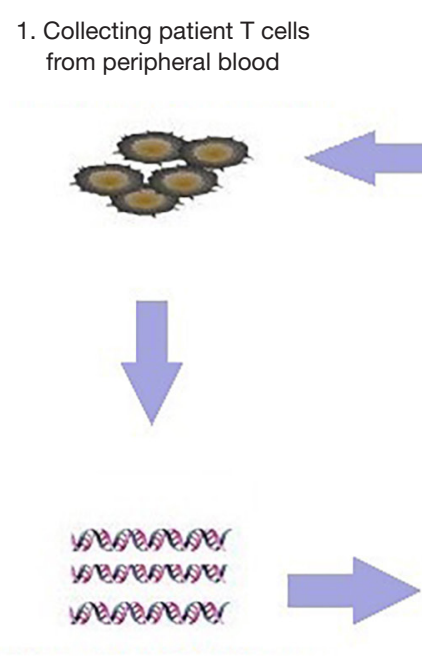

2. Insertion of CAR genes

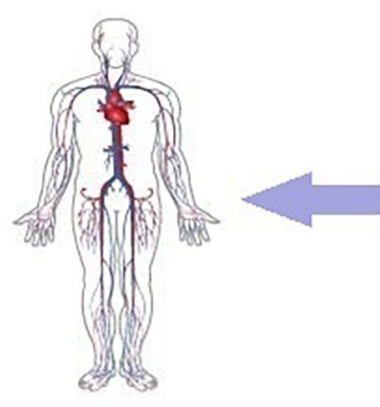

5. Transferring CAR-T cells into patients
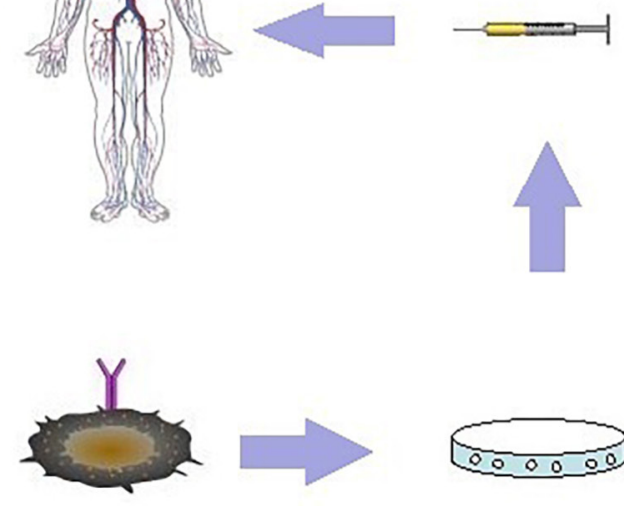

3. CAR-modified T cells

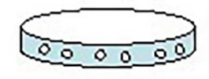

4. Expansion of CAR-T cells

Figure 1 The treatment process for chimeric antigen receptor T cell therapy. T cells are collected from patients' peripheral blood. Then the chimeric antigen receptor genes were inserted into $\mathrm{T}$ cells. The chimeric antigen receptor $\mathrm{T}$ cells are expanded in vitro and then transferred back to patients.

form of a single chain variable fragment derived from a monoclonal antibody, a transmembrane structure, and one or more intracellular $\mathrm{T}$ cell signaling sequences (7). Tumorspecific antigens are not yet well defined except for CD19, which is a B cell lineage-specific antigen that is expressed on malignant $B$ cells in patients with B-ALL, CLL and B cell NHL (8). CAR-modified T cells with specificity against CD19 have demonstrated significant promise against highly refractory hematologic malignancies $(9,10)$. Inspiring clinical outcomes with high complete remission (CR) rates (90\%) have been reported in children and adults with refractory ALL, CLL and lymphoma (11-13).

Recently, Turtle et al. reported that 27 of 29 patients (93\%) achieved leukemic blasts in bone marrow (BM) remission in the treatment of B-ALL after lymphodepletion chemotherapy by CD19 CAR-T cells (14). Bhoj et al. reported a clinical trial about CD19-CAR T persistence in CTL019-treated patients (13). Their study showed that several vaccines remain relatively stable for at least 6-12 months after treatment. Moreover, the persistence of CAR $\mathrm{T}$ cell was different between autologous recipients (average of 201 days) and allogeneic recipients (51 days) (12). However, the clinical outcome varies among different studies. In Brudno's study, only 8 of 20 patients obtained remission, which included two partial remissions (15). The critical factors for better efficacy still remain unclear. In this review, we discuss the key clinical factors affecting response rates of CAR T cells targeting CD19 in B-lineage malignancies including B-ALL, B-CLL and lymphoma.

We present the following article in accordance with the Narrative Review reporting checklist (available at http:// dx.doi.org/10.21037/tcr-20-1044).

\section{CD19-CAR T cell therapy for B cell malignancies}

B cell malignancies are derived from $B$ cells in diverse differentiation stages (16). However, different kinds of $\mathrm{B}$ cell malignancies share a few common B-cell linage markers for targeted therapy. CD19 is a B-lineage-specific transmembrane glycoprotein expressed during all stages of B-cell differentiation (17). CAR T cell therapy is believed as an effective therapeutic approach because of its powerful efficacy on malignant hematological diseases, notably B cell malignancies. CAR-T cell therapy targeting CD19 has exhibited promising prospect in patients with $\mathrm{B}$ cell malignancies including B-ALL, CLL and B cell NHL $(14,18,19)$. Nevertheless, patients treated with CD19-CAR $\mathrm{T}$ therapy have shown different response rates.

\section{Potential factors of CD19-CAR therapy in B cell malignancies}

It is 20 years since the general concept of the CAR T cell was devised. The technology of redirecting T-cell 
Tumor cell

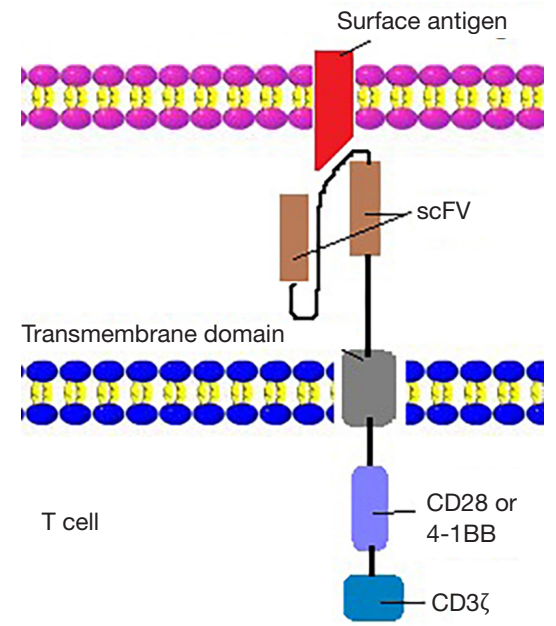

Figure 2 The second generation chimeric antigen receptor structure and interaction between chimeric antigen receptor $\mathrm{T}$ cells and tumor cells.

function has been translated into clinical application during this relatively short period of time. Several groups have reported anti-tumor effects of CD19-directed CAR T cells in patients with $\mathrm{B}$ cell malignancies $(7,18,19)$. However, the response rates of CAR $\mathrm{T}$ cells in the immunotherapy of $\mathrm{B}$ cell malignancies have varied widely. It is still unclear about the critical factors of improving the efficacy of CD19-CAR $\mathrm{T}$ cell therapy in B-lineage malignancies. T cell persistence, lymphodepletion, the treatment of $\mathrm{T}$ cells with $\mathrm{CD} 3 / \mathrm{CD} 28$ beads and IL-2 administration are the potential critical factors of $T$ cells associated with response rate of CD19CAR $T$ cell therapy.

\section{T cell persistence}

Since CAR T cells must persist for a sufficient period of time to ensure successful tumor elimination, insufficient $T$ cell persistence is considered as a critical challenge of CAR-T therapy (20). The persistence of adoptively transferred CAR $\mathrm{T}$ cells was positively correlated with clinical response rates in B-cell malignancies (21). Although the efficacious method of enhancing the persistence of CAR-modified $T$ cells has not been developed, the potential factors have been reported, which include lymphodepletion and patient tumor burden (22). Recently, studies have indicated that $\mathrm{T}$ cell persistence and anti-tumor functions can be improved by re-directed homing of $\mathrm{T}$ cells to the bone marrow (22).

\section{Lymphodepletion}

Lymphodepletion, also called conditioning chemotherapy, may reduce the tumor burden of patients. Lymphodepletion could make new niches for infused CAR T cells by reducing resident cell populations $(23,24)$. Lymphodepletion will enhance the persistence of $T$ cells, which was administrated before the $\mathrm{T}$ cell infusion $(25,26)$. Some studies have shown an inverse relationship between the persistence of CAR T cells and the patients' tumor burden $(21,27,28)$. Conditioning chemotherapy-administrated patients are likely to achieve better clinical benefits.

\section{CAR designing}

The first generation CARs were designed to connect an antibody-derived $\mathrm{scFv}_{\mathrm{v}}$ to the $\mathrm{CD} 3 \mathrm{z}$ intracellular signaling domain of the $\mathrm{T}$ cell receptor through hinge and transmembrane domains. However, because of the lack of costimulation in tumor cell targets, the first-generation CARs showed limited expansion and relatively short persistence (29-31). The lack of co-stimulation molecules leads to the immune escape of tumor cells and rapid apoptosis of T-cells $(32,33)$. To solve the above problems, second generation CARs incorporated costimulatory endodomains, including CD28 (34,35), 4-1BB (CD137) (36,37), into CAR molecules (Figure 2). The optimization of the used cytokines and growth conditions are crucial for the expansion and related anti-tumor activity of CAR-T cells (38). CD3/CD28 bead treatment and no IL-2 administration to $\mathrm{T}$ cells were significantly positively associated with better clinical outcomes, compared with irradiation and IL-2 1 treatment to T cells. IL-2 is a cytokine, which was frequently applied to promote the firstgeneration CAR T cells expansion in vitro (26). Secondgeneration CARs induces IL-2 secretion and T cell proliferation upon CAR cross-linking (9). Anti-CD3/CD28 mAb-coated magnetic beads were used to provide an initial signal for stimulating $\mathrm{T}$ cell expansion (39).

In this new but fast-developing field, many novel strategies of designing CARs are developed to improve the efficacy of CAR-T therapy. CRISPR/Cas9 genomic editing might provide a more effective strategy for the designing of CAR-T cell (40). Some studies have shown that the CRISPR gene-edited CAR T cells have higher antitumor 
activities than none-gene-edited CAR T cells (41). These evidences indicated that CRISPR/Cas9 genomic editing is a promising strategy in the modification of CAR T cells.

Moreover, "ON-switch" CARs are designed to control CAR-T cell activity. In this designed CART, small molecules control $\mathrm{T}$ cell therapeutic functions, and therefore, physicians could control the timing, location, dosage of $T$ cell activity and toxicity $(42,43)$. Studies have revealed that "ON-switch" CARs provided a more powerful strategy of the therapy of malignancies $(42,43)$.

\section{Cytokine release syndrome (CRS)}

CRS, which is caused by excessive cytokine production, is usually typified by chills, fevers and other more severe life threatening reactions (44). Neurotoxicity caused by CD19CAR T cells is usually manifest as delirium, somnolence and other severe cases such as seizures and/or stroke-like phenomena (45). CAR-modified $\mathrm{T}$ cell immunotherapy can be complicated by CRS and neurologic toxicity, which in most cases are manageable and reversible (46). Turtle et al. established that high CAR-T cell doses and tumor burden increase the risks of severe CRS and neurotoxicity (7). Indeed, cytokine elevation is directly correlated to tumor burden at the time of CAR-modified $\mathrm{T}$ cell infusions $(9,47,48)$. The grade of CRS might be an important predictive marker for the infections in $\mathrm{B}$ cell malignancies patients treated with CAR-T cells (49).

\section{Allogeneic hematopoietic stem cell transplantation (alloHSCT)}

alloHSCT, which offers advantages to confer longterm remission of $\mathrm{B}$-cell malignancies, may influence the response rate of patients (50). alloHSCT is a therapeutic strategy to reconstruct normal hematopoietic and immune functions by removing tumor cells from patients and transfusing others' hematopoietic stem cells back to them. Although it is unclear whether infusion of allogeneic CARmodified $\mathrm{T}$ cells could improve outcomes after donor lymphocyte infusions, some studies have reported that allogeneic anti-CD19 CAR T cells could effectively treat B-cell malignancies that progress after alloHSCT $(15,51)$.

\section{Future considerations}

B-ALL, CLL and B cell NHL are three main types of B cell malignancies. CD19-CAR T cells therapy has paved the way for B cell malignancy immunotherapies with high response rates and durable remissions $(52,53)$. Nevertheless, the critical factors for better responses of CD19-CAR T cell therapy are still not clear in the treatment of $\mathrm{B}$ cell malignancies (54). T cell persistence, lymphodepletion, CARs designing, CRS and alloHSCT were associated with responses of $\mathrm{B}$ cell malignancies. The method of enhancing the persistence of CAR-modified $\mathrm{T}$ cells should be further optimized, which is believed to lead to better clinical efficacy in treating B cell malignancies (55).

Efforts have been made to improve the efficacy of CD19-CAR T cell therapy in the treatment of B cell malignancies in the past few years. The first-generation CARs were simply designed to contain a single signaling domain which provides an antitumor signal (56). The firstgeneration CARs have limited anti-tumor effect in vivo due to the apoptosis of T cells, and therefore, the secondgeneration CARs were developed with the incorporation of costimulatory domains CD28 or 4-1BB (CD137) $(57,58)$. Compared with the first-generation CARs, the secondgeneration CARs increased the proliferation, persistence and homing of $\mathrm{T}$ cells, improving the efficacy of therapy. The third-generation CARs joined an extra costimulatory molecule based on the second-generation CARs, obviously activating $\mathrm{T}$ cells and prolonging patients' survival (33). In order to solve the problems of the second and third generations of CARs, such as off-target toxicity, the fourthgeneration CARs have been developed. The fourthgeneration CARs further modified the function of $\mathrm{T}$ cells in many ways. For instance, adding suicide gene and expressing IL-2 (59).

To improve the therapeutic effect of CAR-T therapy on malignancies, many new progresses are being carried out. A suicide gene is encoded to ensure the safety of genetically modified cells by selective ablation adoptive transferred cells. Previous studies have indicated that incorporating the suicide genes into the CAR-T cells is a promising strategy to improve the efficacy of CAR-T therapy and lower the side effects by activating the inducible caspase- 9 protein (59-61). Bispecific CARs with the engagement of two TAAs are designed to recognize the tumor cells in a better way (56). For example, it has been proved that CD20CD19 bispecific CAR T cells may provide better efficacy of therapy than CD19-CAR T cell therapy (62). Recent studies have demonstrated that CRS and neurotoxicity are mainly caused by monocyte-derived IL-1 and IL-6 and intervention against IL-1 may successfully tackle both toxicities $(63,64)$. 
The combination of CAR-T therapy and other antitumor therapies provides a new way to improve the therapeutic effect, reduce the risk of tumor evasion and obtain better clinical outcome $(65,66)$. Combined application of conditional chemotherapy and CAR-T therapy has been proven to be more effective than CAR-T therapy alone, providing strong rationales for combining CAR-T cell therapy with other anti-tumor approaches (67). Evidence has shown that the immune checkpoint blockadebased therapy could significantly enhance the efficacy of CAR-T cell therapy $(68,69)$. The administration of PD-1 and PD-L1 blocking antibodies could increase the activity of CAR-T cells. However, its effect is transient and multiple administrations are still necessary to suppress tumor progression. To solve this problem, CAR-T cells were also genetically engineered to overexpress a $\mathrm{PD}-1$ dominant negative receptor (PD-1 DNR), which lacks PD-1 transmembrane and intracellular signaling domains. The results indicated that PD-1 DNR augmented the efficacy of CAR-T cells and had more advantages over antiPD-1 antibodies, such as long half-life and low toxicity (70). There are also other new strategies to block immune checkpoint in CAR-T cells, such as the generation of PD-1 deficient CD19-CAR T cells based on CRISPR/Cas9 gene editing technology $(71,72)$.

In conclusion, CD19 CAR T cell therapy has produced distinct antitumor responses in the treatment of $\mathrm{B}$ cell malignancies. The rapid development of this field has provided many new strategies for improving the therapeutic effect of CAR-T therapy. The combination of CAR-T therapy and other therapies is a promising strategy for the treatment of cancer patients. To improve the efficacy of CAR-T therapy, the critical factors should be further determined and new strategies should also be developed to make these factors more beneficial.

\section{Acknowledgments}

Funding: None.

\section{Footnote}

Reporting Checklist: The authors have completed the Narrative Review reporting checklist. Available at http:// dx.doi.org/10.21037/tcr-20-1044

Conflicts of Interest: All authors have completed the ICMJE uniform disclosure form (Available at http://dx.doi. org/10.21037/tcr-20-1044). The authors have no conflicts of interest to declare.

Ethical Statement: The authors are accountable for all aspects of the work in ensuring that questions related to the accuracy or integrity of any part of the work are appropriately investigated and resolved.

Open Access Statement: This is an Open Access article distributed in accordance with the Creative Commons Attribution-NonCommercial-NoDerivs 4.0 International License (CC BY-NC-ND 4.0), which permits the noncommercial replication and distribution of the article with the strict proviso that no changes or edits are made and the original work is properly cited (including links to both the formal publication through the relevant DOI and the license). See: https://creativecommons.org/licenses/by-nc-nd/4.0/.

\section{References}

1. Hillis J, O'Dwyer M, Gorman AM. Neurotrophins and B-cell malignancies. Cell Mol Life Sci 2016;73:41-56.

2. Sabattini E, Bacci F, Sagramoso C, et al. WHO classification of tumours of haematopoietic and lymphoid tissues in 2008: an overview. Pathologica 2010;102:83-7.

3. Perna F, Sadelain M. Myeloid leukemia switch as immune escape from CD19 chimeric antigen receptor (CAR) therapy. Transl Cancer Res 2016;5:S221-S225.

4. Maude SL, Teachey DT, Porter DL, et al. CD19-targeted chimeric antigen receptor T-cell therapy for acute lymphoblastic leukemia. Blood 2015;125:4017-23.

5. Avanzi MP, Brentjens RJ. Emerging Role of CAR T Cells in Non-Hodgkin's Lymphoma. J Natl Compr Canc Netw 2017;15:1429-37.

6. Milone MC, Bhoj VG. The Pharmacology of T Cell Therapies. Mol Ther Methods Clin Dev 2018;8:210-21.

7. Turtle CJ, Riddell SR, Maloney DG. CD19-targeted chimeric antigen receptor-modified $\mathrm{T}$ cell immunotherapy for B cell malignancies. Clin Pharmacol Ther 2016;100:252-8.

8. Stamenkovic I, Seed B. CD19, the earliest differentiation antigen of the B cell lineage, bears three extracellular immunoglobulin-like domains and an Epstein-Barr virusrelated cytoplasmic tail. J Exp Med 1988;168:1205-10.

9. Brentjens RJ, Davila ML, Riviere I, et al. CD19-targeted $T$ cells rapidly induce molecular remissions in adults with chemotherapy-refractory acute lymphoblastic leukemia. Sci Transl Med 2013;5:177ra38. 
10. Allegra A, Innao V, Gerace D, et al., Adoptive immunotherapy for hematological malignancies: Current status and new insights in chimeric antigen receptor $\mathrm{T}$ cells. Blood Cells Mol Dis 2016;62:49-63.

11. Maude SL, Frey N, Shaw PA, et al. Chimeric antigen receptor $\mathrm{T}$ cells for sustained remissions in leukemia. $\mathrm{N}$ Engl J Med 2014;371:1507-17.

12. Kebriaei P, Singh H, Huls MH, et al. Phase I trials using Sleeping Beauty to generate CD19-specific CAR T cells. J Clin Invest 2016;126:3363-76.

13. Bhoj VG, Arhontoulis D, Wertheim G, et al. Persistence of long-lived plasma cells and humoral immunity in individuals responding to CD19-directed CAR T-cell therapy. Blood 2016;128:360-70.

14. Turtle CJ, Hanafi LA, Berger C, et al. CD19 CAR-T cells of defined CD4+:CD8+ composition in adult B cell ALL patients. J Clin Invest 2016;126:2123-38.

15. Brudno JN, Somerville RP, Shi V, et al. Allogeneic T Cells That Express an Anti-CD19 Chimeric Antigen Receptor Induce Remissions of B-Cell Malignancies That Progress After Allogeneic Hematopoietic Stem-Cell Transplantation Without Causing Graft-Versus-Host Disease. J Clin Oncol 2016;34:1112-21.

16. Scott DW, Gascoyne RD. The tumor microenvironment in B cell lymphomas. Nat Rev Cancer 2014;14:517-34.

17. Ramos CA, Savoldo B, Dotti G. CD19-CAR trials. Cancer J 2014;20:112-8.

18. Porter DL, Hwang WT, Frey NV, et al. Chimeric antigen receptor $\mathrm{T}$ cells persist and induce sustained remissions in relapsed refractory chronic lymphocytic leukemia. Sci Transl Med 2015;7:303ra139.

19. Lee DW, Kochenderfer JN, Stetler-Stevenson M, et al. T cells expressing CD19 chimeric antigen receptors for acute lymphoblastic leukaemia in children and young adults: a phase 1 dose-escalation trial. Lancet 2015;385:517-28.

20. Lamers CH, Willemsen R, van Elzakker P, et al. Immune responses to transgene and retroviral vector in patients treated with ex vivo-engineered T cells. Blood 2011;117:72-82.

21. Brentjens RJ, Riviere I, Park JH, et al. Safety and persistence of adoptively transferred autologous CD19targeted $\mathrm{T}$ cells in patients with relapsed or chemotherapy refractory B-cell leukemias. Blood 2011;118:4817-28.

22. Zhu Y, Tan Y, Ou R, et al. Anti-CD19 chimeric antigen receptor-modified $\mathrm{T}$ cells for $\mathrm{B}$-cell malignancies: a systematic review of efficacy and safety in clinical trials. Eur J Haematol 2016;96:389-96.

23. Khan AB, Carpenter B, Sousa PSE, et al. Redirection to the bone marrow improves $\mathrm{T}$ cell persistence and antitumor functions. J Clin Invest 2018;128:2010-24.

24. Williams KM, Hakim FT, Gress RE. T cell immune reconstitution following lymphodepletion. Semin Immunol 2007;19:318-30.

25. Curran KJ, Pegram HJ, Brentjens RJ. Chimeric antigen receptors for $\mathrm{T}$ cell immunotherapy: current understanding and future directions. J Gene Med 2012;14:405-15.

26. Wang S, Wang Z. Efficacy and safety of dendritic cells cocultured with cytokine-induced killer cells immunotherapy for non-small-cell lung cancer. Int Immunopharmacol 2015;28:22-8.

27. Dai H, Zhang W, Li X, et al. Tolerance and efficacy of autologous or donor-derived $\mathrm{T}$ cells expressing CD19 chimeric antigen receptors in adult B-ALL with extramedullary leukemia. Oncoimmunology 2015;4:e1027469.

28. Park JR, Digiusto DL, Slovak M, et al. Adoptive transfer of chimeric antigen receptor re-directed cytolytic $\mathrm{T}$ lymphocyte clones in patients with neuroblastoma. Mol Ther 2007;15:825-33.

29. Pule MA, Savoldo B, Myers GD, et al. Virus-specific T cells engineered to coexpress tumor-specific receptors: persistence and antitumor activity in individuals with neuroblastoma. Nat Med 2008;14:1264-70.

30. Till BG, Jensen MC, Wang J, et al. Adoptive immunotherapy for indolent non-Hodgkin lymphoma and mantle cell lymphoma using genetically modified autologous CD20-specific T cells. Blood 2008;112:2261-71.

31. Kershaw MH, Westwood JA, Parker LL, et al. A phase I study on adoptive immunotherapy using gene-modified $\mathrm{T}$ cells for ovarian cancer. Clin Cancer Res 2006;12:6106-15.

32. Maly K, Schirmer M. The Story of CD4 (+) CD28(-) T Cells Revisited: Solved or Still Ongoing? J Immunol Res 2015;2015:251657.

33. Tang XY, Sun Y, Zhang A, et al. Third-generation CD28/4-1BB chimeric antigen receptor $T$ cells for chemotherapy relapsed or refractory acute lymphoblastic leukaemia: a non-randomised, open-label phase I trial protocol. BMJ Open 2016;6:e013904.

34. Maher J, Brentjens RJ, Gunset G, et al. Human T-lymphocyte cytotoxicity and proliferation directed by a single chimeric TCRzeta /CD28 receptor. Nat Biotechnol 2002;20:70-5.

35. Cruz CR, Micklethwaite KP, Savoldo B, et al. Infusion of donor-derived CD19-redirected virus-specific $\mathrm{T}$ cells for B-cell malignancies relapsed after allogeneic stem cell transplant: a phase 1 study. Blood 2013;122:2965-73. 
36. Imai C, Mihara K, Andreansky M, et al. Chimeric receptors with 4-1BB signaling capacity provoke potent cytotoxicity against acute lymphoblastic leukemia. Leukemia 2004;18:676-84.

37. Carpenito C, Milone MC, Hassan R, et al. Control of large, established tumor xenografts with genetically retargeted human T cells containing CD28 and CD137 domains. Proc Natl Acad Sci U S A 2009;106:3360-5.

38. Zhang H, Ye ZL, Yuan ZG, et al. New Strategies for the Treatment of Solid Tumors with CAR-T Cells. Int J Biol Sci 2016;12:718-29.

39. Frauwirth KA, Thompson CB. Activation and inhibition of lymphocytes by costimulation. J Clin Invest 2002;109:295-9.

40. Liu X, Zhang Y, Cheng C, et al. CRISPR-Cas9mediated multiplex gene editing in CAR-T cells. Cell Res 2017;27:154-7.

41. Ren J, Liu X, Fang C, et al. Multiplex Genome Editing to Generate Universal CAR T Cells Resistant to PD1 Inhibition. Clin Cancer Res 2017;23:2255-66.

42. Wu CY, Roybal KT, Puchner EM, et al. Remote control of therapeutic $\mathrm{T}$ cells through a small molecule-gated chimeric receptor. Science 2015;350:aab4077.

43. Juillerat A, Marechal A, Filhol JM, et al. Design of chimeric antigen receptors with integrated controllable transient functions. Sci Rep 2016;6:18950.

44. Bugelski PJ, Achuthanandam R, Capocasale RJ, et al. Monoclonal antibody-induced cytokine-release syndrome. Expert Rev Clin Immunol 2009;5:499-521.

45. Xu XJ, Tang YM. Cytokine release syndrome in cancer immunotherapy with chimeric antigen receptor engineered T cells. Cancer lett 2014;343:172-8.

46. Li S, Yang Z, Shen J, et al. Adoptive therapy with CAR redirected $\mathrm{T}$ cells for hematological malignancies. Sci China Life Sci 2016;59:370-8.

47. Kochenderfer JN, Dudley ME, Kassim SH, et al. Chemotherapy-refractory diffuse large B-cell lymphoma and indolent B-cell malignancies can be effectively treated with autologous $\mathrm{T}$ cells expressing an anti-CD19 chimeric antigen receptor. J Clin Oncol 2015;33:540-9.

48. Kochenderfer JN, Dudley ME, Feldman SA, et al. B-cell depletion and remissions of malignancy along with cytokine-associated toxicity in a clinical trial of anti-CD19 chimeric-antigen-receptor-transduced $\mathrm{T}$ cells. Blood 2012;119:2709-20.

49. Park JH, Romero FA, Taur Y, et al. Cytokine Release Syndrome Grade is a Predictive Marker for Infections in Relapsed or Refractory B-cell All Patients Treated with
CAR T Cells. Clin Infect Dis 2018;67:533-40.

50. Hosing C, Saliba RM, McLaughlin P, et al. Long-term results favor allogeneic over autologous hematopoietic stem cell transplantation in patients with refractory or recurrent indolent non-Hodgkin's lymphoma. Ann Oncol 2003;14:737-44.

51. Heiblig M, Salles G, Thomas X. Allogeneic anti-CD19 CAR T cells: new perspectives in the treatment of B-cell malignancies that progress after allogeneic stem cell transplantation? Transl Cancer Res 2016;5:S5-S8.

52. Ruella $\mathrm{M}$, June $\mathrm{CH}$. Chimeric antigen receptor $\mathrm{T}$ cells for B cell neoplasms: choose the right CAR for you. Curr Hematol Malig Rep 2016;11:368-84.

53. Park JH, Geyer MB, Brentjens RJ. CD19-targeted CAR T-cell therapeutics for hematologic malignancies: interpreting clinical outcomes to date. Blood 2016;127:3312-20.

54. Bonifant CL, Jackson HJ, Brentjens RJ, et al. Toxicity and management in CAR T-cell therapy. Mol Ther Oncolytics 2016;3:16011.

55. Brown CE, Adusumilli PS. Next frontiers in CAR T-cell therapy. Mol Ther Oncolytics 2016;3:16028.

56. Gross G, Waks T, Eshhar Z. Expression of immunoglobulin-T-cell receptor chimeric molecules as functional receptors with antibody-type specificity. Proc Natl Acad Sci U S A 1989;86:10024-8.

57. Kowolik CM, Topp MS, Gonzalez S, et al. CD28 costimulation provided through a CD19-specific chimeric antigen receptor enhances in vivo persistence and antitumor efficacy of adoptively transferred $\mathrm{T}$ cells. Cancer Res 2006;66:10995-1004.

58. Milone MC, Fish JD, Carpenito C, et al. Chimeric receptors containing CD137 signal transduction domains mediate enhanced survival of $\mathrm{T}$ cells and increased antileukemic efficacy in vivo. Mol Ther 2009;17:1453-64.

59. Zhang $\mathrm{E}, \mathrm{Xu} \mathrm{H}$. A new insight in chimeric antigen receptor-engineered $\mathrm{T}$ cells for cancer immunotherapy. J Hematol Oncol 2017;10:1.

60. Yagyu S, Hoyos V, Del Bufalo F, et al. An Inducible Caspase-9 Suicide Gene to Improve the Safety of Therapy Using Human Induced Pluripotent Stem Cells. Mol Ther 2015;23:1475-85.

61. Jones BS, Lamb LS, Goldman F, et al. Improving the safety of cell therapy products by suicide gene transfer. Front Pharmacol 2014;5:254.

62. Martyniszyn A, Krahl AC, André MC, et al. CD20-CD19 Bispecific CAR T Cells for the Treatment of B-Cell Malignancies. Hum Gene Ther 2017;28:1147-57. 
63. Norelli M, Camisa B, Barbiera G, et al. Monocyte-derived IL-1 and IL-6 are differentially required for cytokinerelease syndrome and neurotoxicity due to CAR T cells. Nat Med 2018;24:739-48.

64. Giavridis T, van der Stegen SJC, Eyquem J, et al. CAR T cell-induced cytokine release syndrome is mediated by macrophages and abated by IL-1 blockade. Nat Med 2018;24:731-8.

65. Ramello MC, Haura EB, Abate-Daga D. CAR-T cells and combination therapies: What's next in the immunotherapy revolution? Pharmacol Res 2018;129:194-203.

66. Wang L, Yao R, Zhang L, et al. Chimeric antigen receptor $T$ cell therapy and other therapeutics for malignancies: Combination and opportunity. Int Immunopharmacol 2019;70:498-503.

67. Dudley ME, Wunderlich JR, Yang JC, et al. Adoptive cell transfer therapy following non-myeloablative but lymphodepleting chemotherapy for the treatment of patients with refractory metastatic melanoma. J Clin Oncol 2005;23:2346-57.

Cite this article as: Liu J, Wang L, Yang H, Xing M, Liu S, Yu Z, Ma L. A narrative review of critical factors for better efficacy of CD19 chimeric antigen receptor $T$ cell therapy in the treatment of B cell malignancies. Transl Cancer Res 2020;9(9):5655-5662. doi: 10.21037/tcr-20-1044
68. Cherkassky L, Morello A, Villena-Vargas J, et al. Human CAR T cells with cell-intrinsic PD-1 checkpoint blockade resist tumor-mediated inhibition. J Clin Invest 2016;126:3130-44.

69. Yoon DH, Osborn MJ, Tolar J, et al. Incorporation of Immune Checkpoint Blockade into Chimeric Antigen Receptor T Cells (CAR-Ts): Combination or Built-In CAR-T. Int J Mol Sci 2018;19:340.

70. Chen N, Morello A, Tano Z, et al. CAR T-cell intrinsic PD-1 checkpoint blockade: A two-in-one approach for solid tumor immunotherapy. Oncoimmunology 2016;6:e1273302.

71. Choi BD, Yu X, Castano AP, et al. CRISPR-Cas9 disruption of PD-1 enhances activity of universal EGFRvIII CAR T cells in a preclinical model of human glioblastoma. J Immunother Cancer 2019;7:304.

72. $\mathrm{Hu} \mathrm{W}, \mathrm{Zi} \mathrm{Z}$, Jin $\mathrm{Y}$, et al. CRISPR/Cas9-mediated PD-1 disruption enhances human mesothelin-targeted CAR $\mathrm{T}$ cell effector functions. Cancer Immunol Immunother 2019;68:365-77. 